Johannes Kabatek

\title{
Entrevista con Olaf Blixen sobre Eugenio Coseriu en Montevideo
}

\section{Nota preliminar}

La entrevista cuya transcripción presentamos a continuación se realizó en agosto del 2008 en Montevideo en la casa del Dr. Olaf Blixen (1922-2010) ${ }^{1}$, antropólogo y miembro del Círculo Lingüístico de Montevideo en los años $1950^{2}$. Yo había oído el nombre de Olaf Blixen por primera vez durante las entrevistas hechas a Coseriu sobre los años de Montevideo para el libro Die Sachen sagen, wie sie sind, que publiqué con Adolfo Murguía ${ }^{3}$. En verano del 2008, durante los días de celebración del congreso de la ALFAL en la capital uruguaya, Adolfo Elizaincín me ayudó a conseguir la dirección de Olaf Blixen, quien me recibió, junto a su hija Matilde Paulina, en su casa en el centro de la ciudad, una casa-biblioteca cuyas habitaciones respiraban libro y erudición. Blixen me dedicó muy generosamente una tarde entera y no dejó que me fuera sin llevarme toda una colección de separatas y trabajos sobre temas antropológicos, la mayor parte de ellos publicados en la revista Moana que él mismo había dirigido. Sabemos que para Coseriu, los años montevideanos fueron los más fértiles de su vida, es allí que se escribe gran parte de la obra más conocida y que se elabora la concepción fundamental de la teoría del lenguaje ${ }^{4}$, es allí donde escribe gran parte de su obra más conocida y elabora la concepción fundamental de su teoría del lenguaje. Olaf Blixen nos da una impresión del impacto que tuvo la llegada de Coseriu a Montevideo y nos retrotrae al ambiente intelectual del Montevideo de los años 50, mostrándonos cómo, al coincidir en la ciudad un variado grupo de estudiosos cosmopolitas, esta se convirtió en uno de los centros lingüísticos de mayor proyección internacional de la época. ${ }^{5}$

1 Álvaro Mones, en su bio-bibliografía (consultada el 22-XI-12 y publicada bajo http://mna.gub.uy/innovaportal/file/3672/1/blixen_1922_2010_1.pdf) caracteriza a Blixen de la manera siguiente: "Hombre de una inmensa cultura, un verdadero erudito, políglota, además del español, su lengua materna, dominaba el francés, inglés, portugués, italiano, alemán, latín, además de algunos idiomas de Oceanía, como el pascuense, tongano y samoano y leía árabe y persa. Su prodigiosa y envidiable memoria le permitía no sólo citar autores clásicos de memoria, sino que también letras de tangos o de viejas murgas, conocía detalles de peleas de box, carreras de caballos, partidos de fútbol o partidas clásicas de ajedrez (Lo vi ganar una partida, él jugando a ciegas. Su padre había sido un destacado ajedrecista, que se trataba con grandes maestros, como CAPABLANCA o ALEKHINE, y organizó el Primer Torneo Sudamericano de Ajedrez en el Hotel Carrasco en 1921), y un interminable etcétera de conocimientos con que siempre nos sorprendía e ilustraba."

2 Agradecemos a Anna Hein la primera transcripción de la entrevista y a Álvaro Mones y a Adolfo Elizaincín sus valiosos comentarios.

3 Kabatek, Johannes / Murguía, Adolfo (1997):,Die Sachen sagen, wie sie sind...“. Eugenio Coseriu im Gespräch, Tübingen: Narr. En la pág. 88, Coseriu dice acerca de las actividades de publicación en Montevideo: "Es wurden auch Arbeiten veröffentlicht über Themen, mit denen der eine oder der andere freiwillige Mitarbeiter sich beschäftigte; z.B. von Blixen La traducción literaria und eine Arbeit über die alten Eingeborenensprachen von Uruguay, die nicht mehr existieren, aber teilweise rekonstruiert wurden."

4 Como dice Coseriu mismo: "En Uruguay he desarrollado mi teoría lingüística en todo lo esencial, de suerte que mucho de lo que he publicado después (y de lo que sigo publicando) procede de manuscritos, esbozos y notas de mi época uruguaya." Coseriu, Eugenio (1993): "Discurso pronunciado por el doctor Don Eugenio Coseriu con motivo de su investidura como Doctor honoris causa", en: Discursos pronunciados en el acto de investidura de doctor "Honoris causa" del excelentísimo señor Eugenio Coseriu, Granada: Universidad de Granada, 25.

5 Véase también Blixen, Olaf (1955): "La lingüística en el Uruguay; sus objetivos inmediatos”, Boletín de la Sociedad de Antropología del Uruguay, 2, 1 (2), 23-40. 
$\mathrm{OB}=$ Olaf Blixen; MPB=Matilde Paulina Blixen; JK=Johannes Kabatek

JK: ¿Usted ya vivía en Montevideo cuando llegó Coseriu en el 50?

OB: Sí, yo vivía en Montevideo: nací en Montevideo. Soy completamente uruguayo.

JK: ¿A pesar del apellido?

OB: Sí, a pesar del apellido. Mi abuelo paterno era sueco. Allí está un diploma que designa a mi abuelo Caballero de la Orden de Vasa porque era un hombre que ayudaba a los marinos, a los barcos suecos y noruegos que venían por aquí a hacer pesca; barcos balleneros que aparentemente serían bastante dañosos para el medio ambiente. Pero era allá por 1860.

JK: Otra época en que se pensaba diferente...

OB: Está firmado por el rey de Suecia de la época, Óscar. Entonces yo lo conocí a Coseriu en la época en que estaba casado, todavía con su esposa anterior Margarita Cardu, aunque estaba de hecho medio separado, lo que se notó después.

JK: Que era uruguaya.

OB: Era hija de italiano.

JK: Sí, italiano-uruguayas ¿no?

OB: Sí, eran tres hermanas, por lo menos, y un hermano. Eso es lo que yo recuerdo, ¿no? La mayor era Rosina, después había otra, María me parece que era la segunda; la tercera Margarita. Y además me parece que había un mozo, Cardu también, que era ex-combatiente de la guerra de Etiopía, Umberto me parece. Entonces Margarita llegó, y todavía no estaba Coseriu en Montevideo. Llegó unos meses después.

JK: Llegó en marzo del 50.

OB: No me acuerdo exactamente, pero debe ser así. Físicamente lo conocí cuando ya lo habían nombrado director del Instituto de Filología.

JK: Eso fue un año después; fue en el 51 que lo nombraron.

OB: Sí.

JK: Sí, sí. Tardó un poco.

OB: Sí, claro porque seguramente Coseriu no era conocido aquí. En Uruguay las noticias de Culturales más o menos en serio llegaban despacito.

JK: Tampoco era muy conocido en aquella época ¿no?

OB: No claro. Tenía sus títulos de universidades italianas, creo.

JK: De Roma.

OB: Sí de Roma tal vez, yo no sé. Y formaba parte del Sodalizio milanese.

JK: Exacto.

OB: El que creo que dirigía Vittore Pisani ${ }^{6}$ que después fue suegro de Coseriu cuando se casó con un de sus hijas. Bueno entonces Coseriu, aparentemente por lo que hizo, vino con la idea

6 Vittore Pisani (1899-1990), lingüista italiano. 
de hacer algo que tuviera como modelo el Sodalizio milanese porque trató de reunir gente que se interesara en la lingüística: algunos en la gramática normativa, otros en filología, otros en temas parecidos. Entonces a mí me invitaron por esa época y nos reuníamos en una sala del Instituto de Filología - se le dio ese nombre - del cual se le nombró a Coseriu como jefe o director. Y allí estuvo, en ese local, hasta que Coseriu consiguió la cátedra que le dieron en Tübingen. Entonces Coseriu se preocupaba bastante, por cierto, de que los colaboradores, los que íbamos allí desinteresadamente, consiguiéramos también vinculaciones en el extranjero, sobre todo los que publicábamos algunas cosas de cierta importancia. El Instituto las mandaba por su cuenta y Coseriu se ocupaba de esa acción de propaganda y de difusión - las dos cosas iban juntas. Así por ejemplo Coseriu recomendaba mucho el Dictionnaire étymologique de la langue latine, de Ernout y Meillet, y sabíamos que los autores eran personalidades de primer nivel en el mundo, Meillet como indoeuropeísta y Ernout como latinista. Y Ernout me mandó con motivo de las cosas que yo le mandé una carta que tengo siempre atesorada como el más importante elogio que me dieron en la vida. Le había enviado mis traducciones, al español, en edición bilingüe, de las Nugae de Catulo, y decía: Je trouve votre traduction à la fois élégante et exacte. Elle m'a donné une haute idée des études classiques en Uruguay - lo cual era un error completo porque acá no había nada de importancia. Pero el hecho de que dijera eso que era mucho decir, señala mucho más que unas cuantas frases amables de unos señores que no entienden nada ni del contenido de la traducción ni de otras cosas. Y allí tengo la carta guardada. Bueno, Coseriu organizaba en el Instituto que dirigía reuniones, no sé si decir semanales, pero eran reiteradas con temas que generalmente versaban - cuando hablaba él, que la mayoría de las veces llevaba la voz cantante - sobre la familia indoeuropea y las lenguas más conocidas, pero también sobre lenguas poco conocidas.

También formaban parte del "Sodalizio uruguayo" los profesores de esa época que eran egresados de facultades italianas, Guido Zannier ${ }^{7}$, que fue más tarde director del Instituto, y Giovanni Meo Zilio ${ }^{8}$, que se había graduado en Italia. Iban además una serie de personas que en el Uruguay eran bastante conocidas y que generalmente procedían de la enseñanza media y no de una facultad de filología o de una carrera de filología ni de lingüística ya que todavía no estaba estructurada como tal. Aunque se empezaba a hacer una especie de licenciatura en letras. Yo mismo también tuve una época que fui profesor de la facultad y fui profesor de la Universidad de Buenos Aires, la UBA. Pero esto in illo tempore...

Entonces allí iba también Piccardo ${ }^{9}$, que era un poco más viejo que yo. La señora de Larrobla $^{10}$, que era también profesora y directora de alguna institución de enseñanza media, e hizo un libro de enseñanza del español para muchachos de enseñanza media, Mittelschule ¿no? Y estaba también Marcianó ${ }^{11}$, que era italiano y se dedicaba a la filosofía.

MPB: ¿Ferrario ${ }^{12}$ tuvo que ver?

OB: Ferrario tuvo que ver, el profesor Benigno Ferrario también fue uno de los invitados. Pero Benigno Ferrario era un lingüista de categoría. Él había sido graduado en el Istituto Universitario Orientale di Napoli. Ferrario había anclado en el Uruguay bastantes años antes, era mucho mayor que yo. Cuando yo tenía más o menos treinta años o tal vez menos que

7 Guido Zannier, lingüista uruguayo de origen italiano, †1996.

8 Giovanni Meo Zilio, nacido en Treviso en 1923, lingüista, crítico literario y estudioso de la influencia italiana en la lengua rioplatense, más tarde político en Italia; †2006.

$9 \quad$ Luis Juan Piccardo (1912-1967)

10 Nieves Aragnouet de Larrobla

11 Francesco E. Marcianó

12 Benigno Ferrario 
treinta años, Ferrario era un hombre que tenía setenta o más; era de otra generación; generación y media más viejo que yo. Benigno Ferrario fue muy buena persona, pero era difícil. Había tenido un cargo de traductor para el poder judicial, para la Suprema Corte de Justicia tal vez. Yo lo visité más tarde cuando nos hicimos bastante amigos y viví [¿vivía? Creo que Blixen nunca vivió en la calle Carlos María Ramírez, pero puedo estar equivocado. "vivía" hace más sentido con el texto] entonces en la calle Carlos María Ramírez, en la ruta hacia el Cerro de Montevideo. Tenía una editio princeps de Champollion y tenía otras cosas de mucho valor. Después esa biblioteca, que era notable, pasó a la biblioteca nacional; con materiales del British Museum y de otros lugares. Realmente era un hombre tratado con el respeto que merecía un individuo importante. Y su especialidad eran las lenguas cushitas, o sea las lenguas que se hablaban en Etiopía. Aquí no lo miraban muy bien en esa época, tuvo unas dificultades porque le agarró la época de la guerra y él era buen italiano, no era otra cosa, de manera que a pesar de había estado aquí mucho tiempo, mantenía sus relaciones con los círculos de intelectuales italianos, de linguística y filología. Coseriu lo trataba con gran respeto, y yo también.

$\mathrm{JK}:$ ¿Y cuál había sido su propia formación? ¿Usted era profesor?

OB: No, yo, entre otras cosas, soy abogado. Pero soy fundamentalmente etnólogo. Y además hice cosas de filología como usted ve en mis traducciones de Catulo.

La cuestión era quién también estaba allí - tengo miedo a veces de olvidarme de alguna persona que no debería olvidar - estaba también allí concurriendo un poco después que nosotros, pero en los tiempos de Coseriu, el profesor Nicolás Altuchow ${ }^{13}$. Altuchow es un buen ejemplo del nivel del Uruguay en la época; había tenido el título de magister creo que en indología o en lengua sánscrita, en una universidad, no sé si era la de Lwów. Y Altuchow vino aquí y tuvo que empezar a trabajar de peón. Entonces, después de trabajar con el pico y la pala en una cuadrilla de vino, con una mano atrás y la otra delante, como dice el refrán, entonces Altuchow se fue en un determinado momento a trabajar al Ministerio de Salud Pública para hacer listas de difuntos, muy poco ameno. Entonces estuvo un tiempo y yo conseguí más tarde, porque tenía amistades que durante mucho tiempo las conservé, conseguí que lo pasaran en comisión a otra dependencia del Estado para que fuera al Museo de Historia Natural, a ocuparse de hacer cosas en la biblioteca, en la organización y la anotación de libros. Y allí estuvo varios años Altuchow. Al mismo tiempo fue nombrado profesor de indología en la facultad. Pero las cátedras daban muy poco dinero entonces. Cuando me dieron mi cátedra me ganaba unas cantidades miserables. No sé, me servirían para sumarlas a otras cosas que me daban más dinero naturalmente. Aquí tengo algunos trabajos de Altuchow; y los que no están aquí, están en la antesala, no del infierno como dice la película, sino en la antesala de libros. Esos libros, como se decía antes de los clásicos, De cosas que se enterara quien las leyere, si las leyere con atención. Altuchow formó parte, pues, de ese sodalizio coseriano. $[\ldots]$

JK: ¿Y cuál fue la relación entre Coseriu y los demás? Parece que él fue como el que llevaba ese círculo, el que era la persona dominante, digamos.

OB: Sí, eso fue así y el círculo siguió vivo mientras Coseriu estuvo. Después, cuando se fue Coseriu, el círculo no sé en que momento desapareció. No sé exactamente cuándo porque las

13 Nicolás Altuchow, *1912 en Kiev; †1983 en Montevideo. 
actividades estaban muy diversificadas y yo iba a veces, pero cuando Coseriu desapareció, la situación cambió. Para mí cambió y yo creo que cambió para todos. [...]

JK: Para ustedes, ¿Coseriu tenía también una vida personal? ¿Tenía amistad con la gente del círculo?

OB: Sí.

JK: ¿Sí?

OB: Tenía amistad. Pero una amistad, yo diría que era una amistad en planos un poco distintos. Porque Coseriu era absorbente y además estaba muy imbuido de su talento y de sus conocimientos. Muy imbuido. [...]

MPB: Mamá decía - fue alumna de Coseriu - que tenía una manera de decir las cosas una vez, así de una manera muy técnica, y que después decía lo mismo pero que todo el mundo lo entendía...que tenía esa manera de exponer las cosas [...]

JK: Yo cuando veo las fotos de la época de Uruguay pienso que se le ve que él está convencido de ser él el que conocía las cosas.

OB: Sí, desde luego, es así. [...] Yo siempre tuve muy buena relación con Coseriu hasta el momento que se fue. Porque un día me enteré de que Coseriu se iba, que le habían designado en la universidad de Tübingen y dije: ¡al fin se le reconocieron sus capacidades! Ya había publicado Sistema norma y habla y una serie de cosas por las cuales se había hecho más conocido con la publicación de la Revista de la Facultad de Humanidades y Ciencias (allí donde yo publiqué entonces por esa misma época esas traducciones de Catulo).

JK: Hay una cuestión muy importante para mí de la que había hablado con Coseriu varias veces. Tenemos en lo que ahora es el Archivo Coseriu dos grandes manuscritos jamás publicados. Uno es La teoría lingüística del nombre propio y el otro es El problema de la corrección idiomática. Son manuscritos muy extensos de esa época que nunca se publicaron porque no los completó. El nombre propio por ejemplo está ahora digitalizado y tiene unas 300 páginas de libro. Y Coseriu decía que faltaba la mitad. La corrección idiomática es parecida y nunca se publicó. ¿Quizás tiene alguna explicación de eso?

OB: Bueno, lo que le puedo decir es poco, pero algo es; porque sobre El nombre propio presentó algo que sería un esbozo de comunicación en una reunión de la Sociedad de Antropología de la cual yo fui secretario general, presidente y otras cosas más (y factótum de cualquier modo), que entonces funcionaba en el Montevideo. [...] Coseriu dio lo que fue una charla, una conferencia sobre el nombre propio que se dio físicamente en el local del Museo Pedagógico, al cual tuvimos que recurrir para dar las charlas relacionadas con los actos programados en las Semanas de Antropología. Fue como la cuarta o quinta Semana de Antropología. Y ese nombre de "semana de" se había tomado de Argentina donde también había algo así. [...] Y puede ser que haya algún resumen sobre lo que dijo en el nombre propio, pero mas bien pienso que no. [...]

JK: Ustedes eran casi de la misma edad ¿no?

OB: Coseriu tenía un año más que yo.

JK: Pero muy parecido.

OB: Sí, de la misma edad. Cuando yo tenía 30 años o 31, él tenía 32. 
JK: ¿Entonces tenían también como una relación de amistad por ser de la misma edad, quizás?

OB: Ah, sí, sí. Y varias veces me visitó a mi casa con la nena, con Eugenia, que era un poquito mayor que mi hija.

OB: Bueno, en principio le he contado más o menos mis relaciones con Coseriu. Me gustaría tener más cosas de decir.

JK: No, pero son muchas cosas y le agradezco realmente todo, además con muchos detalles, todo está muy presente. ¡Mil gracias por todo! 